\title{
Academic Publishing, Internet Technology, and Disruptive Innovation
}

\author{
Haven Allahar
}

\author{
(6 Many well established publishers are struggling to ") \\ come up with new, sustainable business models \\ that work in the digital environment.
}

\author{
Abby Clobridge (2013) \\ Managing Director, Clobridge Consulting
}

\begin{abstract}
After 350 years of operation, the academic journal publishing industry is imbalanced and in flux as a result of the impacts of Internet technology, which has led, over the past 20 years, to the rise of open access publishing. The introduction of open access journals, in the opinion of many researchers, is considered to be a case of disruptive innovation that is revolutionizing the industry. This article analyzes the traditional journal publishing system, the recent open access models of journal publishing as an evolving phenomenon, the nature and extent of open access as a disruptive innovation, and the implications for key stakeholders. The major finding is that open access publishing has gained traction because technology has contributed to lower publication costs, easier access to research articles, and speedier publishing processes. However, the threat posed by open access has not significantly impacted traditional publishers because of strategies employed by the major publishers and slow adoption of open access by some researchers.
\end{abstract}

\section{Introduction}

Academic journals date back more than 350 years, and the dominant publishing model over much of this period has focused on subscription journals circulated among academics in print form with the content mainly focused on the sciences, technology, and medical disciplines (Larivière et al., 2015). These academics were largely members of "learned" societies that sponsored the costs of publication (Correia \& Teixeira, 2005; Solomon, 2012). The early history of scholarly journal publishing was traced to an initiative of the Royal Society of London, whose objective was to promote knowledge dissemination among research colleagues (Larivière et al., 2015; Peters et al., 2016). An industry developed based on literature published by these "learned societies" or that was supplied to commercial publishers, who thrived for many years through the production and dissemination of subscription journals (Correia \& Teixeira, 2005; Solomon, 2012). The growth of subscription journals was fueled by the expansion of commercial publishers who acquired society journals and eventually became an oligopoly of five big companies that command more than
$50 \%$ of journal output, mainly in the science-related disciplines (Larivière et al., 2015; Peters et al., 2017; Solomon, 2012, 2013). The dominance of the subscription model continues to the present in terms of market share and profitability (Forgues \& Liarte, 2013). The subscription model was sustained by payments from universities and libraries, but more recently, this model has come to be viewed as a restraint on access to research, of questionable viability, and even deemed to be unsustainable because of increasing costs (Chang, 2006; Wellen, 2013).

The subscription publishing model still dominates the journal publishing industry, but the development and increased application of Internet technology made the distribution of research much easier and also opened up new opportunities. In the 1990s, with the spread of the Internet, a new competitor entered the publishing business based on a philosophy that knowledge should be open to all, leading to the publishing of open access journals (Solomon, 2013). An open access journal is considered one "in which all content is available freely on the web from day one, either exclusively online or 


\section{Academic Publishing, Internet Technology, and Disruptive Innovation}

\section{Haven Allahar}

parallel with a subscription print version, and which can be accessed by anyone with Internet access" (Laasko et al., 2011).

The rise of open access journals benefitted from the "serials crisis", which described the dilemma faced by libraries of declining budgets alongside rising subscription costs charged by publishers (Miguel et al., 2016). The entry and rapid production of open access journals is considered by several reputable researchers as constituting a disruptive innovation that challenges the dominance of large commercial publishers and their subscription journals, thereby radically changing the industry (Clobridge, 2014b; Lafferty \& Edwards, 2004; Peters et al., 2016; Wellen, 2013). The question of whether open access publishing amounts to a disruptive innovation in the journal publishing industry will be explored later in the article.

Nonetheless, the growing acceptance of open access publishing of science-related research was also spurred by supporting actions taken by governments, universities, and societies, which were formalized in declarations endorsing open access publishing as recorded in the Budapest Open Access Initiative (2002), the Bethesda Statement (2003), and the Berlin Declaration (2003), to which many countries were signatories. Subsequently, open access policies were adopted by many governments, research and educational institutions, and universities across the globe. Significant cases and the relevant years were Copenhagen Business School (2009) in Denmark; Harvard (2008) and California (2013) in the United States; Cambridge (2013), Oxford (2016), and Nottingham (2016) in the United Kingdom. Canada was also a relatively early adopter of open access policies with the examples of the Social Sciences and Humanities Research Council in 2006, the Canadian Institutes of Health Research in 2008, and the Natural Sciences and Engineering Research Council in 2013 (Hewitt, 2014). Similar policies were adopted in the Latin American and the Caribbean region led by the Scientific Electronic Library Online (SciELO; scielo.org), which started in 1978, and the Network of Scientific Journals from the Latin American and Caribbean region, Spain, and Portugal (Redalyc; www.redalyc.org), which started in 2002. Both of these organizations serve most Latin American and Caribbean countries and host a range of publications in the sciences, humanities, and social sciences with free access to over 1,000 journals as at 2017. However, a gap remains in the publishing of social science and business journals, which disadvantages small developing countries such as those in the Caribbean, where science research is at a low level.
As open access publishing developed, the year 2012 was described as a watershed because it witnessed: a researcher-led boycott of the largest traditional publisher, Elsevier; the introduction of new enabling policies by major research funders; increased interest generated in the media and by the public as a result of growing awareness of open access; the publication of the Finch report in the United Kingdom; the launch of an open knowledge repository by the World Bank; and the launch of open data platforms and portals by United Nations agencies that linked open data and open access (Clobridge, 2013). This embrace of open access publishing by governments and key stakeholders, such as libraries, academic researchers, and journal authors, was described as "a solution to a dysfunctional journals market and as a way of realizing the potential of the Internet to enhance impact and productivity of research" (Wellen, 2013). However, open access has not received universal acceptance, especially from researchers in the social sciences and business fields, who have not followed the path of science researchers. Indeed, there is still resistance to open access publishing by some academics who consider that the newer open access journals lack legitimacy and credibility. Nonetheless, this position is changing, as evidenced by the indexing of open access journals in the Web of Science and Scopus (Björk, 2017)

This article aims to create awareness of the emergence of open access publishing and stimulate an increase in publication of research articles, particularly in the Caribbean where a deficiency exists (Iton \& Iton, 2015). The rest of this article discusses the methodology employed, an overview of the publishing landscape, the emergence of open access models of publishing, the argument that open access constitutes disruptive innovation, the impacts, and trends in open access publishing, and context-related conclusions.

\section{Methodology and Theoretical Background}

A qualitative research approach was adopted involving a bibliographic, descriptive, and analytical approach to the collection and distillation of relevant literature on the study area sourced from: the leading digital full-text aggregator databases ABI/Inform (search.proquest.com/ abicomplete) and EBSCOhost (search.ebscohost.com); Google Scholar (scholar.google.ca), recognized as the most comprehensive source for retrieving open access articles; the Directory of Open Access Journals (doaj.org), considered the best source for accessing open access business journals; and Internet searches of websites of the main publishers of relevant content such as the Online 


\section{Academic Publishing, Internet Technology, and Disruptive Innovation}

\section{Haven Allahar}

Information Review (emeraldinsight.com/loi/oir), Publications (www.mdpi.com/journal/publications), Online Searcher (infotoday.com/OnlineSearcher/), and The Scholarly Kitchen (scholarlykitchen.sspnet.org), which is the official blog of the Society for Scholarly Publishing. These data sources were searched using the keywords "academic publishing”, "Internet technology and publishing”, "open access publishing models", "disruptive innovation”, and "journal publishing". Consistent with acknowledged qualitative procedures, the process involved: the researcher as the key instrument for conducting the research; multiple sources of data obtained from peer-reviewed journals and specialist reports; and a theoretical lens that seeks to identify the social and political context of the issues studied and that represents a holistic account to better reflect the complex picture of the study elements (Cresswell, 2009). A thematic analysis of the literature was undertaken to identify patterns across the research data and identify the critical issues through a process of data familiarization, coding, and theme development (Braun \& Clarke, 2006; Rodrigues et al., 2016). The results provided a deeper understanding of the dynamics of the publishing industry, its challenges, and the impacts, implications, and trends likely to be experienced by multiple stakeholders such as authors and academic researchers - including those based in developing countries, readers, university librarians, traditional publishers, scholarly societies, open access journals, academic social networks, and mobile technology users.

The theoretical underpinning of this article is the theory of disruptive innovation the origins of which can be traced to Schumpeter (1950), who introduced the concept of "creative destruction" in the context of the opening of new markets that radically change the economic structure from within, while destroying the old and creating a new structure. The modern development of the concept of disruptive innovation was attributed to Christensen (1997), who studied the impact of destructive technologies on earlier business innovations. Christensen distinguished between sustaining technologies that improve existing products and destructive technologies that result in poor performance in the short term. Such technologies were viewed by Christensen (1997) as "typically cheaper, simpler, smaller, and, frequently more convenient to use" and were thus appealing to new customers. Lewis (2012) emphasized that disruptive innovation usually starts off as an inferior product but provides value through the application of new technologies and business models that enhance access to a new service or product while disrupting the market. These characteristics of cheaper, simpler, and enhanced access to a new product (as a result of new technology) are directly applicable to the case of open access journals.

\section{Overview of the Publishing Landscape}

The subscription journal model evolved slowly until expansion of research resulted in an increase in the creation of journals by commercial publishers who grew through acquisition of society journals (Solomon, 2012). Currently, the commercial production of subscription journals is controlled by five major, for-profit publishers labelled as “The Big Five”: Elsevier (elsevier.com), SpringerVerlag (springer.com), Taylor \& Francis (taylorandfrancis.com), John Wiley \& Sons (www.wiley.com), and Sage (sagepublications.com). Four are headquartered in Europe, and the fifth (Sage) is based in the United States. Described as an oligopoly in the digital era (Larivière et al., 2015), "The Big Five” were responsible for over half of all papers published in peer-reviewed journals in 2013, but they concentrated on the science-related disciplines (Krisch, 2015; Solomon, 2012, 2013). Together, they published more than 8,000 journals in 2014: 2,571 by Elsevier, 2,209 by Springer-Verlag, 1,803 by Taylor \& Francis, 1,604 by John Wiley, and 742 by Sage (International Scientific Institute, 2014).

The dominance of the major publishers of subscription journals was sustained through a strategy of "bundling", which involves selling a mixture of high- and low-impact journals through "Big Deals", mainly to university libraries, at high subscription rates (Wellen, 2013). Through this strategy, libraries, which contributed between $68 \%$ and $75 \%$ of journal revenue, had no option but to buy an entire bundle in order to access particular journals of interest (i.e., there was no cost-effective way to subscribe to only a subset of journals), and they faced complex negotiations if they decided to cancel subscriptions (Solomon, 2013).

On this basis, journal publishing continues to be a very profitable business when judged on the financial results of the leading European publishers, Elsevier and Springer, who recorded revenue growth in excess of $30 \%$ per annum from 2008 to 2012 (Forgues \& Liarte, 2013). The profitability of journal publishing as a business enterprise was also demonstrated by the 2015 industry earnings of $\$ 9$ billion USD, which produced a return of $20 \%$ to $30 \%$ (Fecher \& Wagner, 2016). However, a trend was observed toward the cancellation of "Big Deals", which was attributed to declining library budgets and the 


\section{Academic Publishing, Internet Technology, and Disruptive Innovation}

\section{Haven Allahar}

demonstration effect of libraries that had cancelled subscriptions without adverse reactions from users (Anderson, R., 2017).

Academics have pointed to two significant concerns with subscription journals: the business model utilized and the dissemination of research output. The business model does not provide for any form of revenue to authors, whether royalties or payment for peer-review or editorial services (Lambert, 2015). Further, researchers prefer to have their work disseminated in the most prestigious journals, as well as reach a wide audience, which are conflicting objectives because greater resources may be required to publish the prestigious journals. Also, there is little incentive to publish in lowcost, open access journals because of the prestige factor (Lambert, 2015), which is associated with a journal being ranked by reputable organizations such as the Financial Times (www.ft.com) and the Australian Business Deans Council (www.abdc.edu.au/master-journal-list.php). This situation led to the view of the leading academic journals and universities as "dispensers of status" rather than "purveyors of information and knowledge" (Fox, 2016).

While the development of the Internet ushered in the digital era of publishing, the movement for greater access to published research was driven by librarians (especially through the Scholarly Publishing and Academic Resources Coalition, or SPARC; sparcopen.org), researchers, socioeconomic forces, and the evolution of academic publishing (Fogues \& Liarte, 2013). Thus, these forces led to the emergence of open access publishing in the 1990s as an alternative model to subscription journals (Correia \& Teixeira, 2005; Solomon, 2012). According to Kember (2016), open access "challenges the spiralling costs and price barriers put up by commercial journal publishers [that are] draining library budgets while profiting from academic free labour".

\section{Emergence of Open Access Models}

The recent development of open access within the journal publishing industry witnessed the adoption of different models that vary according to the type of access to articles permitted by publishers. The system of open access publishing is somewhat confusing because open access, in its pure sense, implies that journal articles are freely available on the Internet. However, the introduction of article processing charges led to the creation of several variations of open access journals defined by their degree of openness and classification. Open access options offered by different publishers have been elaborated and debated in the literature (e.g., Burchardt, 2014; Clobridge, 2014a; Eger et al., 2015; Fecher \& Wagner, 2016; Harington, 2017; Jubb et al., 2015; Rodrigues et al., 2016; Solomon, 2013; Wellen, 2013) and can be classified as follows:

- Gold open access: the full content of the article is immediately available to any reader with Internet access regardless of the journal's business model. However, many of the journals published by the top-ranked publishers provide an abstract but charge a fee to read or download an article.

- Diamond open access: open access journals that are totally free of charges because costs are met by societies, sponsors, and universities.

- Green or delayed open access: publishing an article in a subscription journal that is subsequently deposited in a repository becoming accessible after a publisher-imposed embargo period of usually six to twelve months. Authors also can deposit in a library repository or upload to a personal website or a social academic network such as Academia.edu (academia.edu) or ResearchGate (researchgate.net).

- Hybrid open access: a journal operates as a subscription journal but offers the authors an open access option for a processing fee of hundreds or thousands of dollars. This model has been criticized as "double-dipping" because the publishers collect payment from both university libraries and authors, and it has been described as a failed model because this option has not gained the expected popularity, being used by a mere 1 to 2 percent of authors (Bjork, 2012).

The evolution of open access publishing from the mid1990s was traced as passing through three waves: the first wave was the non-acceptance of open access by academics due to doubts about sustainability, quality of peer review, lack of indexing in the Web of Science, and lack of prestige; in the second wave, the subscription journals adopted a strategy of making an electronic version of articles freely available through online portals; and the third wave was the introduction of article processing charges by new publishers BioMed Central and PLOS ONE, both of whom have become major open access publishers (Björk \& Solomon, 2012).

Despite slow but steady growth, concerns remain about publishing in open access journals, including: perceptions questioning the academic calibre of open access journals and possible impacts on career progression 


\section{Academic Publishing, Internet Technology, and Disruptive Innovation}

\section{Haven Allahar}

and tenure if authors publish in such journals; publisher-imposed embargo periods; high costs of article processing charges; sustainability of journal business models; unfamiliarity with the self-archiving option; and visibility and discoverability of materials archived in repositories (Hewitt, 2014). These issues are discussed in the next section, however, a key point is that the "subscription versus open access" journals debate is ongoing in the literature. But, according to Osborne (2015), this debate amounted to a distraction because the issue should not be the cost of access to publications, but ensuring good writing and increased accessibility. Any argument against publishing in an open access journal should not influence an author's decision of where to publish, provided that the quality of the journal's standards is assessed (Björk \& Solomon, 2012). In the view of Ren (2015), openness is about more than accessibility; it facilitates "universal participation in the co-development and co-creation of knowledge".

But, how successful has the open access model been so far, in terms of uptake? At least in the United Kingdom, some evidence suggests that the subscription model is retaining its dominance despite growth in the open access model. Gold open access was adopted by several subscriptions journals, which was reflected in growth of $15 \%$ between 2012 and 2014, however, the hybrid model was the most utilized at $62 \%$ (Jubb et al., 2015). The subscriptions model, although still dominant at $87 \%$, declined by only $1 \%$ over the two-year period. Data from Outsell (2015) showed that open access journals published in 2014 totalled 11,740, which included journals from the Big Five publishers and the second largest open access publisher, Hindawi (hindawi.com). The total number of open access journals that did not charge an author fee amounted to 1,505 (13\%) with growth of $35 \%$ over 2013; 8,044 were hybrid $(69 \%)$ with growth of $9 \%$ and 2,191 (6.2\%) were subscription, which declined by $14 \%$ and was the only model that experienced a decline.

\section{Open Access Publishing and Disruptive Innovation}

The concept of disruptive innovation was applied in its early formulation by Christensen (1997), mainly to firms in the hard-disk drive business during the 1970s and 1980s. However, Christensen also pointed to ongoing disruptive innovation in telecommunications, personal computing, utilities, construction, medicalrelated industries, and offset printing. The concept has now been widely applied to many of the modern industries such as airlines, transportation, consumer buying, and more recently, 3D printing (Hahn et al., 2014). As summarized by King and Baatarogtokh (2015), the key arguments of the theory of disruptive innovation are that: firms in a market who are on an improvement trajectory follow a path of sustaining innovation; customers' needs are overshot; capability to address disruptive threats exists; firms fail because of the disruption; and it was argued that managers tended to disregard lowlevel disruptive actions such as digital printing. King and Baatarogtokh (2015) go on to challenge these assumptions while accepting that the theory is valuable provided it serves as a warning, not a prediction nor a substitute for critical thinking. Here, the insights from the theory of disruptive innovation will be used to illustrate the case of publishing of open access journals, which some researchers view as disrupting the traditional publishing industry (Lafferty \& Edwards, 2004; Peters et al., 2016; Russell et al., 2015; Weeks, 2015; Wellen, 2013).

Lafferty and Edwards (2004) argued that disruptive technologies "disrupt the market, change the industry paradigm and create a whole new market for a new product often driving out the incumbent organisations". The authors applied the theory to universities and the publishing industry, concluding that universities were disrupted by simulation and games technology, telepresence, and online teaching. In turn, the publishing industry was disrupted by electronic versions of scholarly journals supported by online submission of articles, electronic indexing, abstracting and searching, translation services, and the incorporation of multimedia components. This position was challenged by Peters and colleagues (2016), who argued that technological disruption has little connection to innovation if it concentrates on competition among publishing companies while downplaying the role of researchers in publishers' innovations. The authors argued that the theory has too narrow a focus to be valuable to the objectives of publishing because "a scholarship of publishing should provide a critique of the theory.... through alternative theorisations of technology and innovation in publishing" (Peters et al., 2016).

Weeks (2015) criticized the notion of disruptive innovation by highlighting specific anomalies including: the definition of disruptive innovation is too broad and loose and does not clearly distinguish between the meanings of disruption and sustaining behaviour; the 


\section{Academic Publishing, Internet Technology, and Disruptive Innovation}

\section{Haven Allahar}

unit of analysis is not specific whether the reference point is the industry, the technology, the firm, or the firm leaders; and managerial behaviour in dealing with disruption assumes rational action in avoiding the threat of disruption. Weeks (2015) concluded that the theory of disruptive innovation does not fit all situations, so its application should be limited to "instances where the innovation is lower cost, lower performing (on at least one performance dimension), and appeals to a subset of the existing market or a new market". However, the disruptive innovation framework was considered by Weeks as relevant to an understanding of the dynamics of innovation and the actions by firms in introducing lower-performing, lower-cost products that can gain market share. From this perspective, the framework may be applied to the open access journal publishing model.

Wellen (2013) viewed the theory of disruptive innovation as relevant to open access publishing, as evidenced by the creation of megajournals by commercial publishers and massive online open courses, where the discovery, management, utilization, and aggregation of academic and educational material were already disrupting the market. It was further argued that gold open access has all the features of disruptive innovation because it combines new technology (digital distribution of content using the Internet) with a new business model (free distribution to the reader with costs met by the author or an institution) (Lewis, 2012). Gold open access started off at a low tier and in niche fields such as the underserved humanities and social sciences and the business and management disciplines, which explains why open access has been embraced in developing countries, as suggested by the global ranking on adoption with: Brazil (3rd), Chile (7th), India (9th), Venezuela (11th), Turkey (13th), and Mexico (15th) (Lewis, 2012). Further, significant growth in open access publishing was observed in India, Brazil, Nigeria, and Iran, with many new journals being established in these countries (Miguel et al., 2016).

\section{Impacts of Gold Open Access Publishing}

The literature on open access publishing pointed to the critical impacts and implications of the gold open access model of publishing and the trends in the business, the key aspects of which were explored by authors who have published several articles on the subject (Laasko et al., 2017; Lewis, 2012; Ren, 2015; Ware \& Mabe, 2015). Indeed, there are impacts on all major stakeholders, as discussed below.

\section{Impact on authors and individual academics}

Gold open access suits most authors because of wide distribution and use of post-publication review. The concerns of academics about prestige and quality will be diminished with the growing acceptance of open access journals. It was suggested that academics should develop publishing strategies balanced among "metrics, visibility and impact", which facilitate "collaborative mechanisms within institutional academic systems" to achieve sustainable openness (Ren, 2015). Authors based in developing countries, with limited funds and access to foreign exchange, should select diamond open access journals as a first option for publishing because publishing costs are (typically) met by host universities and sponsors (i.e., authors are not charged fees to publish in such journals).

\section{Impact on readers}

Researchers worldwide, and particularly in developing countries, benefit from increased access to the literature and learning, particularly those based in Latin America and the Caribbean who have free access to SciELO, which is indexed in the Web of Science (Packer, 2014), and Redalyc - both of which house over 1,000 journals each covering a range of natural science and social science disciplines - and Sci-Hub (described below) for science topics.

\section{Impact on university libraries}

Libraries are confronting the "serials crisis" caused by increasing subscription costs from journal publishers by themselves working as publishers in an arrangement with university presses and also expanding institutional and subject repositories, thereby disrupting the established publishing ecosystem.

\section{Impact on traditional publishers}

Faculty and students are increasingly gaining access to literature freely through online sources such as Sci-Hub (en.wikipedia.org/wiki/Sci-Hub), which provides free access to millions of journal articles by bypassing paywalls and other restrictions, which has attracted legal challenges by publishers. Traditional journals are also formulating strategies to counter the issue of cancellations of subscriptions by libraries. However, it is expected that traditional journals will continue to survive as long as the prestige label persists. Journal prestige has been maintained through the peer-review system and the indexing of journals, but the development of innovative approaches to peer review such as post-publication review and the creation of alternative metrics have the potential to disrupt the established processes with greater application by open access publishers 


\section{Academic Publishing, Internet Technology, and Disruptive Innovation}

\section{Haven Allahar}

Impact on scholarly societies

Scholarly and professional societies are traditionally responsible for providing journal content and covering the publishing costs of many journals in science disciplines, with funds typically derived from membership fees, grants, and endowments. With articles increasingly becoming available from open access journals, society members must weigh the cost of membership against the value of journal access, and societies must decide whether to form alliances with major publishers to retain a role in journal production.

\section{Impact on open access journal models}

Gold open access is considered the major disruptive innovation in the publishing industry, and its impact will be felt by the hybrid and delayed open access variations, which do not modify the cost structure nor substantially change the view of libraries with regards to paying subscriptions. Green open access, which is a supplement to gold open access, is expected to continue in existence through registering with repositories, but it is still not what "a stable financially sustainable arrangement will look like in detail" (Ware \& Mabe, 2015).

\section{Current Trends in Open Access}

\section{Academic social networks}

Platforms such as Academia.edu and ResearchGate can be viewed as disrupting academic publishing by providing new ways for disseminating, searching, and retrieving research content, and are becoming a major way of providing access to individual author's articles (Laasko et al., 2017), particularly for authors in small developing countries. However, Laasko and colleagues (2017) foresee that publishers will exert influence to restrict distribution if the impact reduces income as happened in the case of Elsevier, which was awarded damages from Sci-Hub for copyright infringement (Schiermeier, 2017).

\section{Mobile technology}

Mobile devices are now in common use: the sales of smartphones and tablets now exceed the sales of PCs, and time spent on digital media takes up an increasing proportion of our daily life - now up to 5.6 hours per day - largely because of mobile devices (Anderson, K., 2017). These devices can be used to research and read open access literature directly from journal websites and the Internet, further disrupting journals that provide immediate access but require online payment to read.

\section{Conclusions}

This article identified the impacts on the key participants in the field of academic publishing and highlighted four significant features of the publishing industry that are immediately relevant to the participants: the creation of subscription journals by large publishing companies as the dominant players in the industry; the emergence of open access journals as an alternative business model; the configuration of the open access model into variations on the theme; and the notion of open access as a form of disruptive innovation. The critical impacts of these features on the publishing industry were presented as an update on recent developments within the industry. The conclusions derived from the discussion are as follows.

First, the position of subscription journals remains intact as a publishing vehicle, and the conclusion is that this status will continue for the medium term because of the policy of acquiring small and medium-size journals, efforts to embrace variations of the open access model and even adopt the payment of article processing charges, and the entrenchment of the image of prestige journal brands that appeal to universities and academics seeking tenure.

Second, open access publishing is gaining in prominence, accounting for a $15 \%$ share in the Web of Science index (Björk, 2017), which provides some legitimacy to open access journals. This trend is beneficial to authors in developing countries, where access to subscription journals for research is typically limited by financial resources, especially outside of academia.

The conclusion is that the process is slow, but this is expected to change in the future as some researchers view open access as the future of journal publishing and the growth experienced in developing countries, such as India, Brazil, Nigeria, and Iran (Miguel et al., 2016). Open access journals are building credibility in the eyes of researchers as with the case of the large open access journals, PLOS ONE and PubMed Central. A gap remains, however, in the publishing of social science and business-related journals, which are areas of particular interest to developing countries such as those of Latin America and the Caribbean, where science research is not well developed (Iton \& Iton, 2015; Troncoso, 2012).

Third, the emergence of alternative models of open access has created confusion in the minds of many re- 


\section{Academic Publishing, Internet Technology, and Disruptive Innovation}

\section{Haven Allahar}

searchers by providing options such as the hybrid open access, which is essentially a subscription journal that includes an option to authors to publish as open access for a fee (Bjork, 2012). The state of confusion is compounded by the continuing change in "processes and policies, practices, and opportunities" (Broome, 2014). The conclusion is that open access publishing was utilized more by the science-related disciplines than the social science and business disciplines, with the latter requiring time to establish its validity in the industry and enter the mainstream (Ponte et al., 2017).

Fourth, the debate about the disruptive impact of open access journals on established journals continues in the literature, however, a clear conclusion can be drawn that the impacts of open access as disruptive innovation are beginning to be experienced. These are manifested in the impacts on university libraries, publishers of subscription journals, scholarly societies, and particularly the publishing processes such as peer review, indexing, and impact measurement as the established quality indicators. But, such impacts do not happen overnight. As Peters and colleagues (2016) put it: "If open access is to be viewed as a publishing innovation it will need more time to develop its scope in consideration of the complex systems, practices, and ideologies in which it prospers".

The publishing business is complex and the emergence of a menu of open access options presents challenges to new researchers seeking to publish research articles and who must come to terms with the requirements. This article contributes to the quest of new researchers to arrive at a greater understanding of the publishing industry, and it aims to increase awareness of the dynamics of open access with the aim of increasing publication of research.

\section{About the Authors}

Haven Allahar is an Adjunct Lecturer in Entrepreneurship and Innovation in the Graduate School of Business of the University of the West Indies in Trinidad and Tobago. Haven has over 40 years of management experience in the public and private sectors of Trinidad and Tobago, having held corporate management positions as $\mathrm{COO}$ at an industrial development company and CEO at both small business development and urban development companies. Over the past 15 years, he was a co-owner and Managing Director of a development planning consulting firm. Haven holds a BSc in Economics from the University of the West Indies in Mona, Jamaica, a Diploma in Hotel Administration from Ryerson University in Toronto, Canada, an MA in Management from American Public University in West Virginia, United States, and a DBA in Entrepreneurship from California Intercontinental University, United States. Specialized training was undertaken in Industrial Project Planning, Financing, and Management at Bradford University, England and the Central School of Planning and Statistics, Warsaw, Poland. Haven's publications are available at Academia. Edu and ResearchGate.

\section{References}

Anderson, K. 2017. Trouble at Hand - How Mobile Devices Perpetuate Weak Business Models. The Scholarly Kitchen, July 24, 2017. Accessed November 1, 2017:

https://scholarlykitchen.sspnet.org/2017/07/24/trouble-handmobile-devices-perpetuate-weak-business-models/

Anderson, R. 2017. When the Wolf Finally Arrives: Big Deal Cancelations in North American Libraries. The Scholarly Kitchen, May 1, 2017. Accessed November 1, 2017:

https://scholarlykitchen.sspnet.org/2017/05/01/wolf-finallyarrives-big-deal-cancelations-north-american-libraries /

Björk, B.-C. 2012. The Hybrid Model for Open Access Publication of Scholarly Articles - A Failed Experiment? Journal of the American Society for Information Science and Technology, 63(8): 1496-1504. https://helda.helsinki.fi/handle/10138/2317

Björk, B.-C. 2017. Scholarly Publishing in Transition - From Restricted to Open Access. Electronic Markets, 27(2): 101-109. http://dx.doi.org/10.1007/s12525-017-0249-2

Björk, B-C., \& Solomon, D. J. 2012. Open Access versus Subscription Journals: A Comparison of Scientific Impact. BMC Medicine, 10(73): 1-10.

https://doi.org/10.1186/1741-7015-10-73

Braun, B. V., \& Clarke, V. 2006. Using Thematic Analysis in Psychology. Qualitative Research in Psychology, 3(2): 77-101. http://dx.doi.org/10.1191/1478088706qp063oa 


\section{Academic Publishing, Internet Technology, and Disruptive Innovation}

\section{Haven Allahar}

Broome, M. E. 2014. Open Access Publishing: A Disruptive Innovation. Nursing Outlook, 62(2): 69-71. http://dx.doi.org/10.1016/j.outlook.2014.02.004

Burchardt, J. 2014. Researchers Outside APC-Financed Open Access: Implications for Scholars Without a Paying Institution. Sage Open, 4(4). http://dx.doi.org/10.1177/2158244014551714

Chang, C. C. 2006. Business Models for Open Access Journals Publishing. Online Information Review, 30(6): 699-713. http://dx.doi.org/10.1108/14684520610716171

Christensen, C. M. 1997. The Innovator's Dilemma: When New Technologies Cause Great Firms to Fail. Boston, MA: Harvard Business School Press.

Clobridge, A. 2013. You Say You Want a Revolution? Open Access on the March. Online Searcher, 37(2): 39-43.

Clobridge, A. 2014a. Open Access: Progress, Possibilities, and the Changing Scholarly Communications Ecosystem. Online Searcher, 38(2): 42-52.

Clobridge, A. 2014b. All Things Open: Open Access as the Entry Point to Open Knowledge. Online Searcher, 39(1): 38-41.

Correia, A. M. R., \& Teixeira, J. C. 2005. Reforming Scholarly Publishing and Knowledge Communication: From the Advent of the Scholarly Journal to the Challenges of Open Access. Online Information Review, 29(4): 349-364.

https://doi.org/10.1108/14684520510617802

Creswell, J. W. 2009. Research Design: Qualitative, Quantitative, and Mixed Methods Approaches (3rd ed.). Thousand Oaks, CA: SAGE Publications.

Eger, T., Scheufen, M., \& Meierrieks, D. 2015. The Determinants of Open Access Publishing: Survey Evidence from Germany. European Journal of Law and Economics, 39(3): 475-503. http://dx.doi.org/10.1007/s10657-015-9488-X

Fecher, B., \& Wagner, G. G. 2016. Open Access, Innovation, and Research Infrastructure. Publications, 4(2): 1-8. http://dx.doi.org/10.3390/publications4020017

Forgues, B., \& Liarte, S. 2013. Academic Publishing: Past and Future. M@n@gement, 16(5): 739-756.

http://doi.org/10.3917/mana.165.0739

Fox, J. 2016. Academic Publishing Is All About Status. Bloomberg View, January 5, 2016. Accessed November 1, 2017: https://www.bloomberg.com/view/articles/2016-01-05/academicpublishing-is-all-about-status

Harington, R. 2017. Diamond Open Access, Societies and Mission. The Scholarly Kitchen, June 1, 2017. Accessed November 1, 2017: https://scholarlykitchen.sspnet.org/2017/06/01/diamond-openaccess-societies-mission/

Hahn, F., Jensen, S., \& Tanev, S. 2014. Disruptive Innovation vs Disruptive Technology: The Disruptive Potential of the Value Propositions of 3D Printing Technology Startups. Technology Innovation Management Review, 4(12): 27-36. http://timreview.ca/article/855

Hewitt, T. 2014. Open Access in Canada: Towards a Common Policy for Federal Funding Agencies. Paper presented at the RUCK International Open Access Meeting, March 20, 2014, London, UK.
Iton, I. \& Iton, A. 2015. Open Access and the Caribbean Academic: An Exploratory Investigation of the Adoption of this Medium for Publishing among Science Faculty of the University of the West Indies. IFLA Journal, 42(1): 25-35.

http:/dx.doi.org/10.1177/0340035215616977

Jubb, M., Goldstein, S., Amin, M., Plume, A., Aisati, M., Oeben, S., Pinfield, S., Bath, P., Salter, J., Johnson, R., Fosci, M. 2015. Monitoring the Transition to Open Access: A Report for Universities $U K$. Research Information Network (RIN), Elsevier, University of Sheffield, and Research Consulting.

Kember, S. 2016. Why Publish? Learned Publishing, 29(S1): 348-353. http://dx.doi.org/10.1002/leap.1042

King, A. A., \& Baatarogtokh, B. 2015. How Useful Is the Theory of Disruptive Innovation? MIT Sloan Management Review, 57(1): 7790

Krisch, J. 2015. These Five Corporations Control Academic Publishing. Vocativ, June 10, 2015. Accessed November 1, 2017: http://www.vocativ.com/culture/science/five-corporationscontrol-academic-publishing/

Lafferty, S., \& Edwards, J. 2004. Disruptive Technologies: What Future Universities and Their Libraries? Library Management, 25(6/7): 252-258. https://doi.org/10.1108/01435120410699636

Lambert, C. 2015. The "Wild West" of Academic Publishing: The Troubled Present and Promising Future of Scholarly Communication. Harvard Magazine, January-February: 56-83. https://harvardmagazine.com/2015/01/the-wild-west-ofacademic-publishing

Larivière, V., Haustein, S., \& Mongeon, P. 2015. The Oligopoly of Academic Publishers in The Digital Era. PLOS ONE, 10(6): e0127502.

https://doi.org/10.1371/journal.pone.0127502

Laasko, M., Lindman, J., Shen, C., Nyman, L., \& Björk, B. 2017. Research Output Availability On Academic Social Networks: Implications for Stakeholders in Academic Publishing. Electronic Markets, 27(2): 125-133.

http://dx.doi.org/10.1007/s12525-016-0242-1

Lewis, D. W. 2012. The Inevitability of Open Access. College \& Research Libraries, 73(5): 493-506.

Miguel, S., de Oliveira, E. F. T., \& Grácio, M. C. C. 2016. Scientific Production on Open Access: A Worldwide Bibliometric Analysis in the Academic and Scientific Context. Publications, 4(1): 1 . http://dx.doi.org/10.3390/publications4010001

Osborne, R. 2015. Open Access Publishing, Academic Research and Scholarly Communication. Online Information Review, 39(5): 637-648.

http://dx.doi.org/10.1108/OIR-03-2015-0083

Osborne, R. 2013. Why Open Access Makes No Sense. In N. Vincent \& C. Wickham (Eds.), Debating Open Access: 96-105. London: The British Academy.

Outsell. 2015. Open Access 2015: Market Size, Share, Forecast, and Trends. Burlingame, CA: Outsell, Inc.

Packer, A. L. 2014. SciELO Citation Index in the Web of Science. SciELO in Perspective, February 28, 2014. Accessed November 1, 2017:

http://blog.scielo.org/en/2014/02/28/scielo-citation-index-in-theweb-of-science/ 


\section{Academic Publishing, Internet Technology, and Disruptive Innovation}

\section{Haven Allahar}

Peters, M. A., Jandrić, P., Irwin, R., Locke, K., Devine, N., Heraud, R., Gibbons, A., Besley, T., White, J., Forster, D., Jackson, L., Grierson, E., Mika, C., Stewart, G., Tesar, M., Brighouse, S., Arndt, S., Lazaroiu, G., Mihaila, R., Legg, R., \& Benade, L. 2016. Towards a Philosophy of Academic Publishing. Educational Philosophy and Theory, 48(14): 1401-1425.

http://dx.doi.org/10.1080/00131857.2016.1240987

Ponte, D., Mierzejewska, B. I., \& Klein, S. 2017. The Transformation of the Academic Publishing Market: Multiple Perspectives on Innovation. Electronic Markets, 27(2): 97-100. http://dx.doi.org/10.1007/s12525-017-0250-9

Ren, X. 2015. The Quandary between Communication and Certification the Individual Academics' Views on Open Access and Open Scholarship. Online Information Review, 39(5): 682-697. https://doi.org/10.1108/OIR-04-2015-0129

Rodrigues, R. S., Taga, V. \& dos Passos, M. F. 2016. Research Articles about Open Access Indexed by Scopus: A Content Analysis. Publications, 4(4): 31.

http://dx.doi.org/10.3390/publications4040031

Russell, B., Bessant, J., \& Brown, S. 2015. Dealing with Disruption: A Sector Study of Exploitation and Exploration in Academic Publishing. In Proceedings of the XXVI International Society of Professional Innovation Management (ISPIM) Conference Shaping the Frontiers of Innovation Management, June 14-17 June, Budapest, Hungary.

Schiermeier, Q. 2017. US Court Grants Elsevier Millions in Damages from Sci-Hub. Nature News, June 22, 2017. Accessed November 1, 2017:

https://www.nature.com/news/us-court-grants-elsevier-millionsin-damages-from-sci-hub-1.22196
Schumpeter, J. A. 1950. Capitalism, Socialism, and Democracy (3rd ed.). New York: Harper \& Row.

Solomon, D. J. 2012. Digital Distribution of Academic Journals and Its Impact on Scholarly Communications: Looking Back After 20 Years. The Journal of Academic Librarianship, 39(1): 23-28. http://dx.doi.org/10.1016/j.acalib.2012.10.001

Solomon, D. J. 2013. Types of Open Access Publishers in Scopus. Publications, 1(1): 16-26. http://dx.doi.org/10.3390/publications1010016

Troncoso, J. D. 2011. Role of Open Access in the Emergence and Consolidation of Refereed Journals in Latin America and the Caribbean. Higher Education and Society Magazine, 16(2): 1-21.

Ware, M., \& Mabe, M. 2015. The STM Report an Overview of Scientific and Scholarly Journal Publishing (4th ed.). The Hague, Netherlands: International Association of Scientific, Technical and Medical Publishers.

Weeks, M. R. 2015. Is Disruption Theory Wearing New Clothes or Just Naked? Analyzing Recent Critiques of Disruptive Innovation Theory. Innovation: Management, Policy \& Practice, 7(4): 417-428. http://dx.doi.org/10.1080/14479338.2015.1061896

Wellen, R. 2013. Open Access, Megajournals, and MOOCs: On the Political Economy of Academic Unbundling. Sage Open, 3(4). http://dx.doi.org/10.1177/2158244013507271

Citation: Allahar, H. 2017. Academic Publishing, Internet Technology, and Distruptive Innovation. Technology Innovation Management Review, 7(11): 47-56. http://doi.org/10.22215/timreview/1120

Keywords: academic publishing, internet technology and publishing, open access publishing models, disruptive innovation, journal publishing 


\section{Academic Affiliations and Funding Acknowledgements}

Canadà
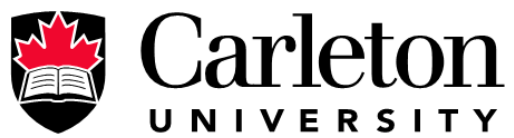

U N I V E R S I T Y

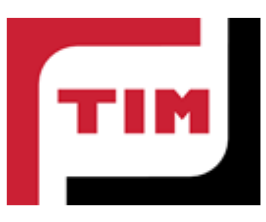

The Federal Economic Development Agency for Southern Ontario (FedDev Ontario; feddevontario.gc.ca) is part of the Innovation, Science and Economic Development portfolio and one of six regional development agencies, each of which helps to address key economic challenges by providing regionallytailored programs, services, knowledge and expertise.

- The TIM Review receives partial funding from FedDev Ontario's Investing in Regional Diversification initiative.

Technology Innovation Management (TIM; timprogram.ca) is an international master's level program at Carleton University in Ottawa, Canada. It leads to a Master of Applied Science (M.A.Sc.) degree, a Master of Engineering (M.Eng.) degree, or a Master of Entrepreneurship (M.Ent.) degree. The objective of this program is to train aspiring entrepreneurs on creating wealth at the early stages of company or opportunity lifecycles.

- The TIM Review is published in association with and receives partial funding from the TIM program. 